\title{
BIBLIOTECA ELETRÔNICA DA EMBRAPA CERRADOS: ESTUDO DE USUÁRIO
}

\author{
BIBLIOTECA ELECTRÓNICA DE EMBRAPA \\ CERRADOS: ESTUDIO DE USUARIOS
}

\begin{abstract}
Maria Elisabeth Salviati - elisabeth.salviati@embrapa.br Doutora em Ciências da Informação pela Universidade de Brasília (UnB). Analista da Empresa Brasileira de Pesquisa Agropecuária (EMBRAPA).

Daniela Henrique de Oliveira Duarte - daniela.duarte@embrapa.br Especialista em Produção de Software com Ênfase em Software Livre pela Universidade Federal de Lavras (UFL). Analista de Sistemas da Empresa Brasileira de Pesquisa Agropecuária
\end{abstract} (EMBRAPA).

\begin{abstract}
RESUMO
Introdução: Apresentam-se os resultados da pesquisa realizada com os usuários da Biblioteca Eletrônica da Embrapa Cerrados, implantada em 2004, que organiza, armazena e disponibiliza na íntegra a produção técnico-científica da Empresa.

Objetivo: Levantar o perfil do usuário e efetuar uma avaliação precisa do sítio. Metodologia: Levantamento de dados demográficos; hábitos; e recursos de consulta: navegação, tempo de carga das páginas, ajuda, leiaute e terminologia por meio de questionário online. Análise de dados pelo aplicativo SPSS - Statistical Package for the Social Sciences.

Resultados: Constata-se que os usuários principais são estudantes e engenheiros-agrônomos, com até 30 anos de idade, oriundos do Distrito Federal, pertencentes às universidades e escolas superiores, que estão em busca de atualizar o conhecimento. Em segundo lugar aparecem os usuários de órgãos públicos; empresas particulares; Embrapa; agronegócios; governo federal; colégios e escolas; associações e organismos não governamentais; extensão rural; cooperativas e sindicatos. Esses usuários não apresentam dificuldades para usar o serviço.

Conclusões: O serviço atende bem. Porém, algumas sugestões de melhoria são úteis para aperfeiçoá-lo. Constata-se pouca demanda oriunda de fazendas, empresas de extensão rural, cooperativas e sindicatos. Esse resultado indica a necessidade de se projetar novos produtos e serviços direcionados a esse outro público.
\end{abstract}

Palavras-chave: Biblioteca digital. Estudo de usuário. Recuperação de informação. Tecnologia agropecuária. 


\section{INTRODUÇÃO}

O benefício principal da biblioteca digital é armazenar documentos em formato digital, que podem ser acessados online por qualquer pessoa de qualquer parte do mundo e a qualquer tempo.

A Biblioteca Eletrônica da Embrapa Cerrados foi criada em 2004 e possui, hoje, quase 2.000 publicações online, geradas pelo corpo de pesquisadores da Empresa. Ela oferece recursos de consulta por hipertexto de autor; título; assunto; e tipo de publicação, além de busca booleana.

O objetivo deste trabalho foi elaborar o estudo de usuário dessa Biblioteca, visando:

a) Levantar e caracterizar o perfil demográfico dos usuários.

b) Levantar e caracterizar os hábitos dos usuários: frequência de uso, formas de consulta e temas buscados.

c) Levantar e caracterizar o nível de satisfação em relação ao serviço prestado.

d) Levantar sugestões para melhorar o serviço e estender sua divulgação.

Estudos de usuários são pesquisas científicas que permitem averiguar a prestação dos serviços de bibliotecas, a partir da perspectiva de quem a utiliza.

Segundo Valls e Vergueiro (2006) ninguém é melhor que o próprio cliente para definir suas necessidades de informação e o nível de qualidade do serviço recebido.

Rozados e Piffer (2009, p. 174) ressaltam que os estudos de usuários possibilitam "[...] identificar e diferenciar as características, os interesses, as necessidades e os hábitos de informação dos usuários reais e potenciais de uma unidade de informação."

As autoras identificam os seguintes objetivos dessas pesquisas:

a) Traçar o perfil dos usuários.

b) Identificar suas necessidades informacionais.

c) Coletar informações para criar ou otimizar serviços.

d) Avaliar os serviços oferecidos.

e) Atingir o usuário potencial por meio de avaliação da demanda de produtos e serviços. 
A quantidade de estudos dessa natureza tem aumentado consideravelmente ao longo dos anos. Baptista e Cunha (2007) salientam que, no Library and Information Science Abstracts (LISA), essa é uma das áreas mais volumosas em termos de produção mundial.

Porém, no que tange à avaliação de bibliotecas digitais, Saracevic (2004) salienta que a maioria dos trabalhos trata de conceitos, abordagens e modelos de avaliação. Poucos relatam avaliações realizadas, em razão de sua complexidade.

$\mathrm{Na}$ revisão de literatura de Liew (2009) sobre bibliotecas digitais no período de 1997 a 2007, de 199 artigos sobre uso e usabilidade, apenas três tratam de questões relativas à percepção do usuário.

Em trabalho mais recente, Hu, Hu e Yan (2014) ressaltam esse fato. Eles afirmam que a maioria dos estudos têm focalizado aspectos, tais como: o serviço em si, a tecnologia empregada, as medidas de usabilidade, acessibilidade, eficiência e interatividade. Porém, poucos têm levado em conta a percepção do usuário. É, também, o que aponta Sheeja (2010).

Porém, é justamente no processo da busca de informação que o envolvimento do usuário é importante para desenvolver ou aprimorar esse processo. Hu, Hu e Yan (2014) mostram que os usuários têm maior percepção dos serviços oferecidos pela biblioteca digital, especificamente, naqueles aspectos que envolvem a recuperação de informação. Eles levantaram os elementos principais de cada um dos cinco serviços oferecidos pelas bibliotecas digitais de 78 universidades da China: serviços de orientação (informações sobre as coleções e os serviços oferecidos); serviços de organização da informação; serviços de interação; serviços de recuperação de informação; e serviços de suporte individual com o objetivo de realizar uma avaliação abrangente.

Foram analisadas 353 respostas dos questionários aplicados ao público acadêmico. As hipóteses levantadas foram analisadas por meio de um modelo de equação estrutural que refinou os achados do levantamento. O modelo construído é uma combinação da análise 
fatorial confirmatória e o método de regressão múltipla que procura identificar quais são os serviços mais influenciados pela percepção do usuário.

Os resultados apontaram os serviços de orientação; de recuperação de informação; e de suporte individual os mais influenciados pela percepção do usuário. Os serviços intermediários, como organização da informação, não interagem com o usuário. Eles só são perceptíveis indiretamente, quando o usuário utiliza o serviço de recuperação de informação ou de suporte individual.

Além de poucos trabalhos sobre a percepção do usuário, também não se recuperaram, na literatura, trabalhos que exploram o uso de bibliotecas digitais da área agrícola. Encontraram-se, porém, alguns trabalhos sobre o uso de bibliotecas digitais universitárias. Entre eles, citam-se os trabalhos de Sheeja (2010) e Brindesi, Monopoli e Kapidakis (2013), que apresentam resultados antagônicos.

Sheeja (2010) investigou os estudantes de graduação em Engenharia com o objetivo de verificar a satisfação do usuário com a biblioteca digital da Cochin University of Science and Technology (CUSAT), Índia.

A coleta de dados foi realizada por meio de questionários distribuídos a 204 estudantes no período de janeiro a setembro de 2009 . A análise foi realizada por meio do Statistical Package for the Social Sciences (SPSS).

De maneira ampla, os resultados apontaram elevada aceitação da biblioteca digital por estudantes de graduação, que mostraram estar satisfeitos com seus recursos e funcionalidades.

Porém, o trabalho de Brindesi, Monopoli e Kapidakis (2013) encontrou resultados diferentes. Ele traz conclusões importantes que podem orientar a melhoria dos sistemas de informação das bibliotecas. Os autores investigaram o comportamento de busca de informação pelo estudante de graduação em Física e Astronomia na Universidade de Atenas, Grécia. A coleta de dados foi por meio de questionários 
distribuídos aos estudantes. Os questionários coletaram informações pessoais; frequência e capacidades de busca de informação; interesse em se atualizar; frequência e razões para usar ou não determinadas fontes de informação; comportamento de busca de informação; preferências de leitura; e métodos utilizados para obter acesso aos artigos de texto completo. Os resultados da amostra de 103 estudantes apontaram que eles preferem usar o Google e material de referência como a Wikipedia e sítios da internet do que as bases de dados mais significativas em sua área de atuação, porque estão mais familiarizados com essas fontes, que são fáceis de usar, têm maior velocidade e facilidade de acesso. Eles constataram, também, que os estudantes usam com pouca frequência os anais de eventos, a Web of Science, a Web of Knowledge e o SPIRES porque é necessário ter conhecimento de regras específicas de recuperação, uso de operadores booleanos e truncagem de termos.

Portanto, os resultados de avaliação quanto à facilidade e à eficiência de determinada biblioteca digital não são passíveis de generalização.

Além disso, várias diferenças em área temática, país de origem, o público podem influenciar os resultados quando se realiza investigação diretamente com os usuários.

Whitmire (2002) ressalta haver diferenças nos estudos conforme o domínio temático da biblioteca. Ela usou o modelo de Biglan para provar que existem diferenças entre os padrões de busca de informação por estudantes de graduação de ciências humanas, puras e biológicas.

Ademais, os resultados podem ser diferentes em diversos países, pois aspectos culturais, socioeconômicos e tecnológicos diferem e são mais acentuados entre os países desenvolvidos e em desenvolvimento.

Em estudo preliminar, Salviati e Castro (2009) avaliaram a Biblioteca Eletrônica da Embrapa Cerrados. Os dados foram coletados no período de dois meses (maio a junho de 2007) por intermédio de um questionário disponível no sítio, cuja finalidade era conhecer a opinião 
dos usuários sobre o serviço oferecido.

Os resultados desse primeiro estudo serão discutidos conjuntamente com os achados deste novo trabalho, que visou levantar o perfil do usuário da Biblioteca Eletrônica e efetuar uma avaliação mais precisa do sítio.

Alguns resultados estatísticos pertinentes dos trabalhos citados serão discutidos no item Resultados e Discussão.

\section{METODOLOGIA}

\subsection{Instrumento de Coleta de Dados}

A coleta de dados foi realizada por meio de um questionário disponibilizado na página da Biblioteca Eletrônica por aproximadamente seis meses, no período de 20 de dezembro de 2010 a 3 de junho de 2011.

Foram coletadas informações sobre o perfil do usuário (características sociais e demográficas, tais como, sexo, idade, escolaridade, profissão, ocupação, instituição, cidade, estado, país) e o sítio da Biblioteca Eletrônica que podem ser resumidas nos seguintes itens:

a) Avaliação da homepage: qual a facilidade, a capacidade de recuperação e a rapidez da busca de informação, a terminologia e o leiaute.

b) Avaliação do conteúdo: assuntos de interesse.

c) Frequência de uso e objetivo de consulta.

Com o objetivo de se colher dados de usuários de toda e qualquer formação e profissão, as questões foram elaboradas em linguagem simples e objetiva. $O$ pré-teste foi realizado aplicando-se 0 questionário por uma semana com a finalidade de averiguar a complexidade das questões, as ambiguidades, a linguagem difícil, a ordem das questões e o tempo de duração. Após a identificação e a correção dos problemas, foi efetuada a coleta pelo período especificado. 


\subsection{Escolha dos Sujeitos}

Todos os usuários que entraram na página da Biblioteca Eletrônica no período de avaliação tiveram que preencher um cadastro. Esse cadastro continha informações demográficas úteis para analisar o perfil do respondente.

Já as questões sobre o sítio só foram preenchidas pelos usuários mais experientes, isto é, aqueles que já tinham consultado a Biblioteca Eletrônica por pelo menos duas outras vezes. Essa exigência teve como objetivo obter informações mais fidedignas sobre o desempenho do serviço, seguindo o requisito básico de estudos de usuários proposto por Figueiredo (1994), que aconselha não indagar sobre serviços e atividades às quais os usuários não têm julgamento de valor.

\subsection{Procedimentos de Análise de Dados}

Os resultados foram analisados utilizando-se o pacote estatístico SPSS - Statistical Package for the Social Sciences e distribuídos em duas vertentes:

a) Perfil demográfico.

b) Avaliação do sítio.

Os dados colhidos pela internet foram armazenados em base de dados Postgres e, posteriormente, exportados para Excel.

Os dados em Excel sofreram o primeiro tratamento. As respostas de perguntas abertas, por exemplo, instituição, assunto pesquisado, opinião sobre leiaute e terminologia, bem como as sugestões, foram agrupadas por afinidades e recodificadas, usando-se códigos padronizados. Esse processo evitou um leque muito grande de opções, que dificultaria a análise. Já os assuntos pesquisados foram classificados em temas e palavras-chave mais específicas dentro de cada assunto, utilizando a Estrutura de assuntos da Embrapa Cerrados (SALVIANTI, 2012).

Criaram-se, portanto, tabelas de profissão e motivo da busca (que incluiu as profissões e os motivos das tabelas originais mais aqueles 
especificados pelo respondente), assuntos, instituição, opinião sobre leiaute, opinião sobre terminologia e sugestões.

Após esse tratamento preliminar os dados foram importados no SPSS e novamente tratados. As variáveis - idade, estado e país - foram reagrupadas em faixas e categorias mais amplas para facilitar a análise.

\section{RESULTADOS E DISCUSSÃO}

Colheram-se 926 respostas do cadastro. Dessas, 303 também responderam ao questionário. Foram escolhidos aqueles que tinham consultado o sítio pelo menos duas outras vezes, correspondendo a $32,72 \%$ do total. Essa porcentagem bastante significativa é de usuários relativamente frequentes.

\subsection{Perfil dos Entrevistados}

A maioria dos respondentes é do sexo masculino, $64,47 \%$ contra 35,53\% feminino, Tabela 1.

Tabela 1 - Usuários da Biblioteca Eletrônica: Gênero

\begin{tabular}{|l|c|c|c|c|}
\hline Sexo & Frequência & $\%$ & \% Válida & \% Acumulada \\
\hline Feminino & 329 & 35,5 & 35,5 & 35,5 \\
\hline Masculino & 597 & 64,5 & 64,5 & 100,0 \\
\hline Total & 926 & 100,0 & 100,0 & \\
\hline
\end{tabular}

Fonte: Dados de pesquisa.

Esses resultados são similares aos encontrados por Brindesi, Monopoli, Kapidakis (2013), em que 59,2\% eram homens e 40,8\%, mulheres. Já o trabalho de $\mathrm{Hu}$, Hu e Yan (2014) apontou pequena diferença entre mulheres $(50,2 \%)$ e homens $(49,9 \%)$.

Pesquisas divulgadas pelo Centro de Estudos sobre as Tecnologias da Informação e da Comunicação no Brasil indicam que os homens são a maioria na web, 52,31\% homens e $47,69 \%$ mulheres 
(PERFIL..., 2012). Porém, a diferença de gênero no estudo do Cetic não foi tão acentuada como neste estudo. Talvez a diferença maior em nossa pesquisa tenha sido pelo fato da Biblioteca Eletrônica ser da área de Agricultura, na qual predomina o sexo masculino.

Tabela 2 - Usuários da Biblioteca Eletrônica: Idade

\begin{tabular}{|l|c|c|c|c|}
\hline \multicolumn{1}{|c|}{ Faixa } & Frequência & $\%$ & \% Válida & $\begin{array}{c}\% \\
\text { Acumulada }\end{array}$ \\
\hline 21 a 30 anos & 344 & 37,15 & 37,19 & 37,19 \\
\hline 31 a 40 anos & 220 & 23,76 & 23,78 & 60,97 \\
\hline 41 a 50 anos & 176 & 19,01 & 19,03 & 80,00 \\
\hline 51 a 60 anos & 93 & 10,04 & 10,05 & 90,05 \\
\hline 11 a 20 anos & 63 & 6,80 & 6,81 & 96,86 \\
\hline 61 anos em diante & 28 & 3,02 & 3,03 & 99,89 \\
\hline 1 a 10 anos & 1 & 0,11 & 0,11 & 100,00 \\
\hline Total & $\mathbf{9 2 5}$ & $\mathbf{9 9 , 8 9}$ & $\mathbf{1 0 0 , 0 0}$ & \\
\hline Em branco & $\mathbf{1}$ & $\mathbf{0 , 1 1}$ & & \\
\hline Total Geral & $\mathbf{9 2 6}$ & $\mathbf{1 0 0 , 0 0}$ & & \\
\cline { 1 - 3 } & & & &
\end{tabular}

Fonte: Dados de pesquisa.

Quanto à idade, houve usuários de todas as faixas etárias, devido ao sítio ser aberto ao público. A maioria $(90,05 \%)$ possui entre 21 a 60 anos. A faixa etária mais frequente é de 21 a 30 anos (37,15\%) (Tabela 2). A faixa etária mais frequente no trabalho de $\mathrm{Hu}$, Hu e Yan (2014) foi de 18 a 24 anos $(58,9 \%)$ e coincide, até certo ponto, com os resultados apurados.

Esse resultado é condizente com os resultados do Cetic, que aponta a faixa de 16 a 24 anos como a mais frequente na web brasileira (PERFIL..., 2012).

A média foi 35 anos, a idade mínima 9 anos e a máxima 86 anos. Já a moda foi de 23 anos.

Quanto à profissão ou ocupação desses usuários, houve grande variedade de respostas: 58 profissões diferentes foram identificadas, e 8 usuários deixaram essa informação em branco.

A maioria dos respondentes é agrônomo ou engenheiro agrícola $(18,85 \%)$. Em segundo lugar aparece o estudante (18,74\%). 
São significativos também: professor e pedagogo $(7,08 \%)$, administrador e gestor (7,08\%), agricultor, pecuarista, aquicultor e apicultor $(4,58 \%)$. Já a participação do extensionista e do técnico agrícola é de 3,16\%.

Apresentam-se, na Figura 1, as 20 ocupações mais frequentes.

Embora exista uma concentração maior de estudantes entre $18 \mathrm{e}$ 26 anos (12,49\%), observa-se que a frequência maior é do profissional já graduado, principalmente agrônomo e, também, de outras áreas: biólogo, veterinário, engenheiros, nutricionista, geógrafo, geólogo, engenheiro ambiental (40,09\%). Esse resultado coincide com o encontrado por Hu, Hu e Yan (2014), em que predomina o usuário já graduado (estudante de mestrado e doutorado).

Figura 1 - Características dos Usuários: Profissão/Ocupação

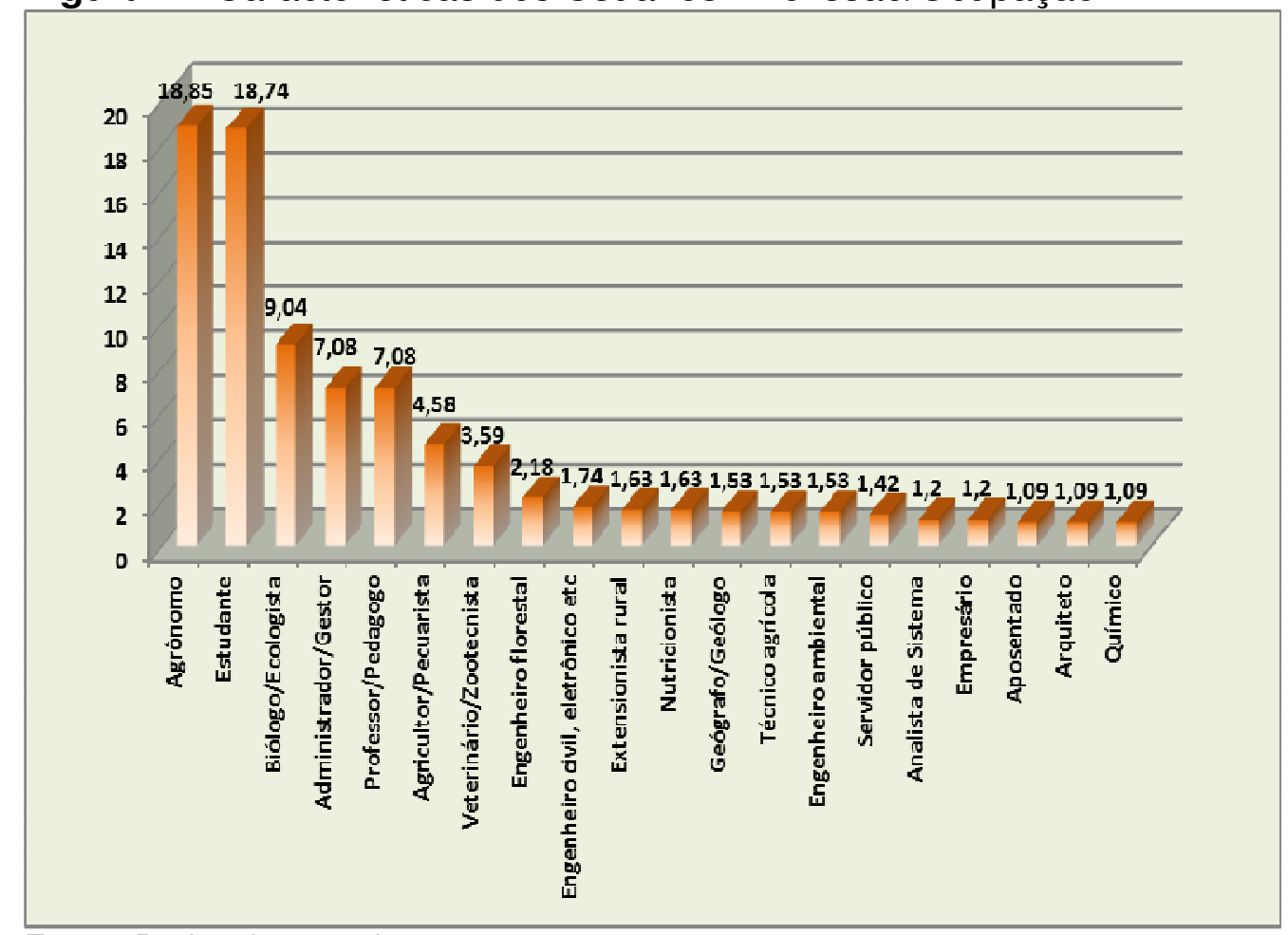

Fonte: Dados de pesquisa.

Confrontando-se esses resultados com a pesquisa anterior de Salviati e Castro (2009), observa-se que, naquele estudo, os estudantes foram mais frequentes $(37,58 \%)$, depois os agrônomos $(21,84 \%)$, professores $(5,13 \%)$, biólogos $(4,24 \%)$ e agricultores $(3,36 \%)$. As outras 
categorias apresentaram baixa frequência, até mesmo os extensionistas rurais que foram apenas 2,83\%. Houve, porém, 18,23\% de respondentes classificados em "Outras Profissões".

$\mathrm{Na}$ pesquisa atual, os resultados foram pulverizados em diversas profissões e ocupações. Algumas, correlatas à área de agropecuária, tais como: biólogo e ecólogo (9,04\%); veterinário e zootecnista (3,59\%); engenheiro florestal (1,74\%); nutricionista (1,63\%); engenheiro ambiental; sanitarista (1,53\%); geógrafo, geólogo e minerólogo (1,53\%); químico e bioquímico $(1,09 \%)$. Outras são periféricas ou, ainda, não condizentes com as linhas de pesquisa da Embrapa Cerrados: engenheiros civis, eletrônico, mecânico, metalúrgico, naval e de telecomunicações $(1,74 \%)$, Técnico de informática $(1,42 \%)$, arquiteto, projetista, desenhista e paisagista $(1,09 \%)$.

Talvez, a explicação para isso seja a diversidade de público que navega na internet, bem como de maior divulgação do sítio da Biblioteca Eletrônica que foi implantada em 2004. Sabe-se, também, que o número de internautas tem duplicado nos últimos anos. Existem 79,9 milhões de internautas no Brasil. O Brasil é o $3^{\circ}$ país mais conectado (BRASIL..., 2013).

O percentual de brasileiros conectados à internet aumentou de $27 \%$ para 48\%, entre 2007 (época da coleta de dados da pesquisa anterior) e 2011 (ano de coleta de dados atual) (DADOS..., 2012).

A maioria das consultas da Biblioteca Eletrônica, como já era esperada, é proveniente do Brasil (98,49\%) (Tabela 3). O sítio e as publicações arroladas encontram-se no idioma Português. Esse fato dificulta a consulta por estrangeiros de outra língua. Dessa forma, apenas $1,51 \%$ das consultas foram provenientes do exterior. Entre elas ressaltam-se Portugal, com 3 usuários; e Colômbia e França, com 2 usuários cada. Entre os outros países, aparecem em maior quantidade aqueles de língua espanhola: Colômbia, Chile, Costa Rica, México e Venezuela.

Os resultados computados na análise publicada em 2009 foram 
semelhantes entre Brasil e exterior. Porém, os países participantes foram diferentes, embora com predominância dos países de língua espanhola (SALVIATI; CASTRO, 2009).

Tabela 3 - Usuários da biblioteca eletrônica: país

\begin{tabular}{|c|c|c|c|c|}
\hline País & Frequência & $\%$ & \% Válida & $\begin{array}{c}\% \\
\text { Acumulada }\end{array}$ \\
\hline Brasil & 912 & 98,49 & 98,49 & 98,49 \\
\hline Portugal & 3 & 0,32 & 0,32 & 98,81 \\
\hline Colômbia & 2 & 0,22 & 0,22 & 99,03 \\
\hline França & 2 & 0,22 & 0,22 & 99,24 \\
\hline Canadá & 1 & 0,11 & 0,11 & 99,35 \\
\hline Chile & 1 & 0,11 & 0,11 & 99,46 \\
\hline Costa Rica & 1 & 0,11 & 0,11 & 99,57 \\
\hline $\begin{array}{l}\text { Estados } \\
\text { Unidos }\end{array}$ & 1 & 0,11 & 0,11 & 99,68 \\
\hline Islândia & 1 & 0,11 & 0,11 & 99,78 \\
\hline México & 1 & 0,11 & 0,11 & 99,89 \\
\hline Venezuela & 1 & 0,11 & 0,11 & 100,00 \\
\hline Total & 926 & 100,00 & 100,00 & \\
\hline
\end{tabular}

Fonte: Dados de pesquisa.

$\mathrm{Na}$ Figura 2, verifica-se que a maioria dos respondentes (50\%) procede da região Centro-Oeste (região de maior concentração do Cerrado). É interessante notar que a região Sudeste também apresenta índice bem significativo $(25,66 \%)$. E, a região Sul, que praticamente não tem Cerrado, aparece com índice mais elevado $(6,25 \%)$ que a região Norte (5,26\%), cujos Estados de Tocantins, Maranhão e Piauí possuem alta concentração de Cerrado.

Esse resultado, no entanto, é praticamente igual àquele da pesquisa publicada em 2009. Naquela ocasião, a classificação foi igual e as porcentagens apresentaram pequena variação (SALVIATI; CASTRO, 2009).

Analisando-se o perfil dos usuários de todas as regiões brasileiras em conjunto, construíram-se perfis mais frequentes, mostrados na Tabela 4, que representam 14,91\% dos usuários brasileiros. Nota-se a participação maior da região Centro-Oeste, que 
possui o maior número de usuários (456). E, a participação bastante significativa, também, da região Sudeste, embora com aproximadamente a metade do número de usuários (234).

Figura 2 - Características dos Usuários: Regiões Brasileiras

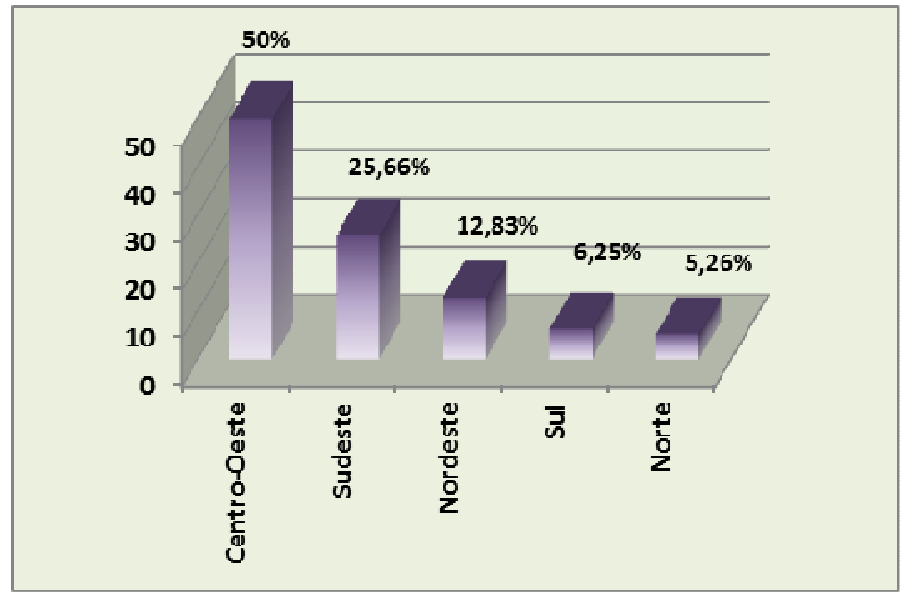

Fonte: Dados de pesquisa.

Tabela 4 - Perfis dos Usuários Brasileiros da Biblioteca Eletrônica

\begin{tabular}{|c|c|c|c|c|}
\hline Profissão/Ocupação & Região & Gênero & Faixa etária & Frequência \\
\hline Estudante & Centro-Oeste & Feminino & 11 a 20 anos & 19 \\
\hline $\begin{array}{l}\text { Engenheiro Agrônomo } \\
\text { ou Agrícola }\end{array}$ & Centro-Oeste & Masculino & 21 a 30 anos & 18 \\
\hline $\begin{array}{l}\text { Engenheiro Agrônomo } \\
\text { ou Agrícola }\end{array}$ & Sudeste & Masculino & 21 a 30 anos & 18 \\
\hline Estudante & Sudeste & Masculino & 21 a 30 anos & 15 \\
\hline Estudante & Centro-Oeste & Masculino & 21 a 30 anos & 15 \\
\hline $\begin{array}{l}\text { Engenheiro Agrônomo } \\
\text { ou Agrícola }\end{array}$ & Centro-Oeste & Masculino & 31 a 40 anos & 13 \\
\hline Estudante & Sudeste & Feminino & 21 a 30 anos & 13 \\
\hline $\begin{array}{l}\text { Engenheiro Agrônomo } \\
\text { ou Agrícola }\end{array}$ & Nordeste & Masculino & 21 a 30 anos & 13 \\
\hline Biólogo/Ecologista & Sudeste & Feminino & 21 a 30 anos & 12 \\
\hline \multicolumn{4}{|l|}{ Subtotal } & 136 \\
\hline \multicolumn{4}{|l|}{ Outros perfís } & 776 \\
\hline \multicolumn{4}{|l|}{ Total de respondentes } & 912 \\
\hline
\end{tabular}

Fonte: Dados de pesquisa.

Na Figura 3, mostra-se a porcentagem de usuários por instituição, agrupada em 18 categorias. Entre os 926 respondentes da amostra, 
$41,68 \%$ deixaram essa informação em branco e, não foi possível identificar o tipo da instituição de um usuário. Entre os respondentes, as universidades e escolas superiores foram responsáveis pela maioria das consultas $(47,78 \%)$. Somam-se a essas as escolas técnicas, colégios agrícolas e instituições de ensino com 4,08\%.

Em seguida, aparecem os governos estadual e municipal (10,74\%); Embrapa (6,85\%); governo federal (4,26\%); judiciário $(0,56 \%)$; e legislativo (0,37\%); empresas particulares de diversos ramos $(9,63 \%)$; agronegócios (4,63\%); cooperativas e sindicatos, com $0,37 \%$ cada; instituições de pesquisa, associações e ONGs 2,96\%.

Figura 3 - Características dos Usuários: Instituição

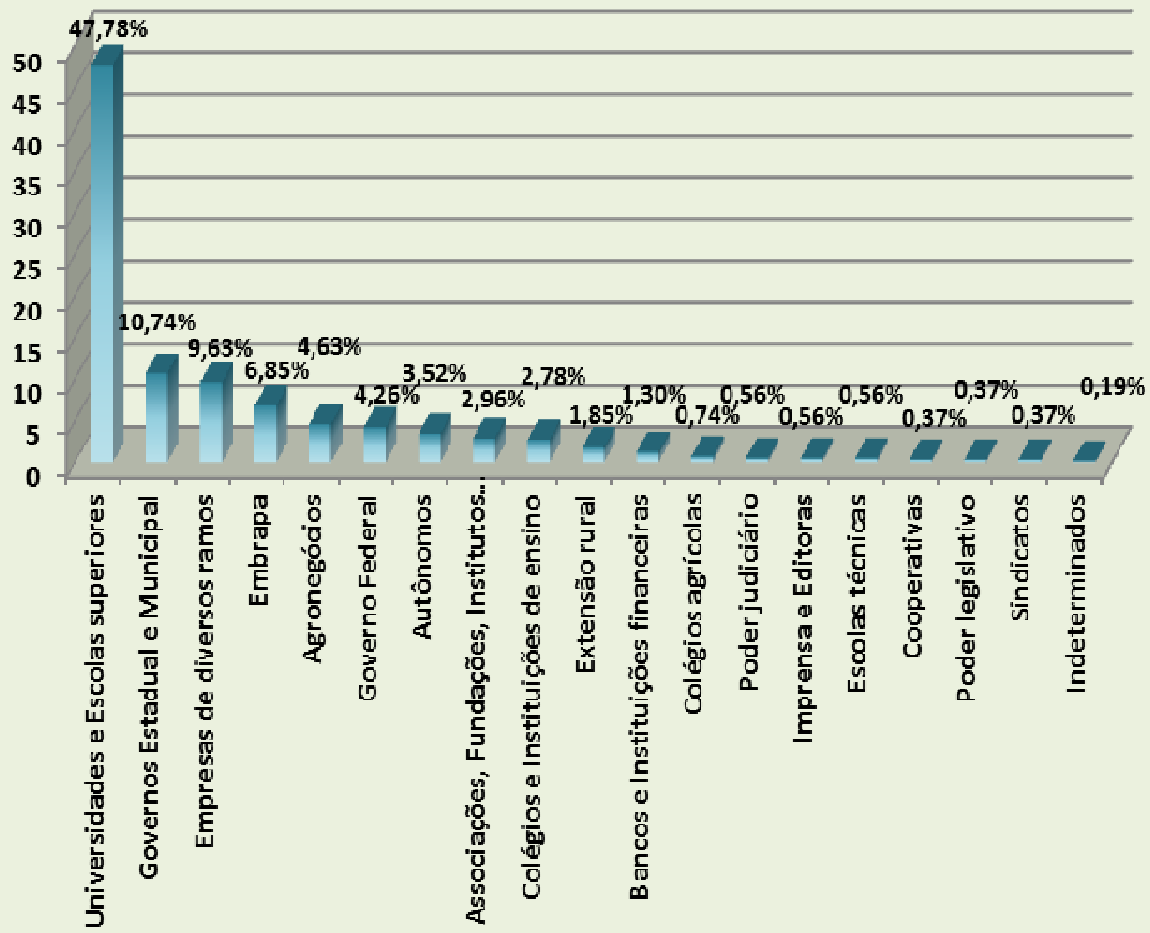

Fonte: Dados de pesquisa.

Na pesquisa anterior, houve muita coincidência com os resultados atuais. Comprovadamente as universidades e escolas de diversos níveis são os usuários de maior frequência seguidos pelos órgãos governamentais (SALVIATI; CASTRO, 2009).

$\mathrm{Na}$ Tabela 5, mostra-se o número de consultas realizadas por 
cada tipo de instituição.

Foram 116 universidades diferentes que consultaram o sítio e geraram frequência total de 258 consultas. É a Universidade Federal de Goiás a que maior número de vezes consultou (22); seguida de perto pela Universidade de Brasília (21). As demais universidades são oriundas dos Estados de Goiás, Mato Grosso, Mato Grosso do Sul, São Paulo, Minas Gerais, Bahia, Paraná, Tocantins e Piauí.

Já nos ensinos médio e fundamental, aparecem as escolas técnicas (3); colégios agrícolas (4); e instituições de ensino em geral (15). No total, foram 21 escolas diferentes.

Com relação às empresas dos governos estadual e municipal, 49 consultaram o sítio. Dessas, 7 tiveram frequência de consulta superior a 1. Destacam-se, com 3 consultas cada: Empresa Baiana de Desenvolvimento Agrícola e a Polícia Civil do Distrito Federal.

Tabela 5 - Usuários da Biblioteca Eletrônica: Instituição

\begin{tabular}{|l|c|c|}
\hline \multicolumn{1}{|c|}{ Instituição } & Quantidade & Número de consultas \\
\hline Universidades & 116 & 258 \\
\hline $\begin{array}{l}\text { Governos estadual e } \\
\text { municipal }\end{array}$ & 49 & 58 \\
\hline Empresas particulares & 52 & 52 \\
\hline Embrapa & 11 & 37 \\
\hline Outros & 35 & 35 \\
\hline Agronegócios & 25 & 25 \\
\hline Governo federal & 23 & 23 \\
\hline $\begin{array}{l}\text { Colégios + Escolas técnicas + } \\
\text { Colégios Agrícolas }\end{array}$ & 21 & 22 \\
\hline $\begin{array}{l}\text { Associações, Fundações e } \\
\text { Instituições de pesquisa e } \\
\text { Ongs }\end{array}$ & 13 & 16 \\
\hline $\begin{array}{l}\text { Extensão rural, cooperativas } \\
\text { e sindicatos }\end{array}$ & 7 & 14 \\
\hline Total & $\mathbf{3 5 2}$ & $\mathbf{5 4 0}$ \\
\hline Em branco & $\mathbf{3 8 6}$ & $\mathbf{3 8 6}$ \\
\hline Total geral & $\mathbf{7 3 8}$ & $\mathbf{9 2 6}$ \\
\hline
\end{tabular}

Fonte: Dados de pesquisa.

Foram 52 as empresas particulares de diversos ramos que consultaram a página, excetuando-se os agronegócios, computados 
separadamente. Todas elas fizeram apenas uma consulta. Foram empresas de atuação tão diversa que não permitiu realizar qualquer agrupamento. Já os agronegócios foram 25 , todos com frequência de consulta igual a 1.

Houve, também, 11 Unidades da própria Embrapa que consultaram a página, sobressaindo em número de consultas realizadas, a Embrapa Cerrados, unidade mantenedora da Biblioteca Eletrônica.

Já 23 órgãos do governo federal nos poderes executivo, legislativo e judiciário realizaram consultas no sítio, sendo o Ministério da Agricultura, Pecuária e Abastecimento o órgão de maior frequência (5), e, em seguida, a Companhia de Desenvolvimento dos Vales do São Francisco e do Parnaíba, com 2 consultas. Os demais órgãos realizaram apenas uma consulta.

Entre as associações, fundações e instituições de pesquisa e as ONGs, destacam-se o Instituto Chico Mendes com três consultas, e o Instituto Refloresta com duas. As demais instituições possuem frequência 1. É interessante ressaltar duas instituições de pesquisa do exterior: IRD (França) e Rainbow Heights Nursery \& Research (EUA).

Poucas consultas foram realizadas pelas instituições de extensão rural, cooperativas e sindicatos. A Emater-MG, a Emater-PB e o Instituto Capixaba de Pesquisa, Assistência Técnica e Extensão Rural aparecem com duas consultas. Ao todo foram sete as instituições de extensão que realizaram consultas, além de dois sindicatos e duas cooperativas.

Esses resultados são globais, incluem usuários de instituições em todos os estados da federação e, também, as estrangeiras. Estratificando-se, porém, esses resultados por região brasileira e somando-se as frequências de cada estado, observa-se que as universidades e escolas superiores aparecem na seguinte ordem: Centro-Oeste (123), Sudeste (65), Nordeste (35), Norte (18) e Sul (15). Ordem similar às instituições de ensino: Centro-Oeste (6), Sudeste (6), Nordeste (2), Norte (1) e Sul (0). 
Os governos estaduais e municipais apresentaram os seguintes resultados: Centro-Oeste (23), Sudeste (12), Nordeste (12), Norte (8) e Sul (3). E o governo federal quase obedeceu a mesma sequência: Centro-Oeste (13), Sudeste (4), Nordeste (3), Sul (2) e Norte (1).

As empresas particulares de diversos ramos foram mais frequentes no Centro-Oeste (22) e Sudeste (20). Em seguida, aparecem Sul (5), Nordeste (4) e Norte (1).

Os agronegócios foram mais frequentes no Centro-Oeste (15), seguido pelos Nordeste (5), Sudeste (3) e Norte (2).

As instituições de pesquisa, associações sem fins lucrativos e organizações não governamentais (ONGs) só aparecem no CentroOeste (8) e Sudeste (5).

Similarmente à pesquisa anterior, a extensão rural teve pouca representatividade $(1,85 \%)$ distribuída na seguinte ordem: Sudeste (4), Nordeste (3), Centro-Oeste (2) e Norte (1) (SALVIATI; CASTRO, 2009).

Comparando-se os resultados em cada estado do Centro-Oeste, verifica-se que o Distrito Federal aparece com predominância de consultas oriundas de universidades e escolas superiores, colégios e instituições de ensino, do governo federal e da própria Embrapa. O Estado de Mato Grosso apresentou a segunda frequência mais alta. Os outros estados apresentaram resultados equilibrados. As consultas provenientes de outros tipos de instituição foram semelhantes entre todos os estados.

$\mathrm{Na}$ região Nordeste, o maior número de consultas proveniente das universidades e das instituições de ensino foi do Estado da Bahia. Os resultados nos outros estados foram bem equilibrados. Também foram equilibrados os resultados dos estados com relação a outros tipos de instituição.

$\mathrm{Na}$ região Sudeste, foi o Estado de Minas Gerais que efetuou maior número de consultas provenientes de universidades e escolas superiores; seguido por São Paulo. Os outros estados apresentaram mesmo resultado. O número de consultas provenientes de outros tipos 
de instituição foi similar entre os diversos estados.

$\mathrm{Na}$ região Norte, sobressaiu o Estado do Tocantins com maior número de consultas de universidades e dos governos estadual e municipal. Os estados de Roraima e Pará aparecem em segundo lugar nas consultas oriundas de universidades. Não houve alteração significativa entre os demais estados. Houve, também, resultados semelhantes entre os diversos estados nas consultas oriundas das demais instituições.

$\mathrm{Na}$ Região Sul, foi o Paraná que apresentou maior número de consultas de universidades. Os outros estados tiveram resultados semelhantes. As consultas oriundas de outros tipos de instituição foram similares entre todos os estados.

Catorze usuários do exterior foram encontrados na amostra. Desses, 6 deixaram a questão sobre o nome da instituição em branco e 1 foi impossível identificar o tipo de instituição a que ele pertencia. Cinco usuários do exterior eram provenientes de universidades: 3 de Portugal e 2 da Colômbia. Outros dois usuários pertenciam a instituições de pesquisa, uma sediada no México e outra nos Estados Unidos.

Da amostra de 926 usuários, 303 responderam ainda questões sobre frequência de consulta da Internet e quais os assuntos buscados na Biblioteca Eletrônica.

Quanto à frequência de consulta da Internet, $48,84 \%$ dos entrevistados a utilizam diariamente; $29,04 \%$, semanalmente; $13,53 \%$, ocasionalmente; e 8,58\%, mensalmente.

A alta frequência de consulta diária, embora surpreendente, não é rara. $\mathrm{Na}$ pesquisa passada, a frequência diária era de $86,55 \%$ (SALVIATI; CASTRO, 2009). A internet é um meio fácil, rápido de obter informação e por isso é um meio muito apreciado pelos usuários. São os canais rápidos e de acesso rápido à informação que têm a preferência dos usuários (BAPTISTA; CUNHA, 2007; HU; HU; YAN, 2014; SHEEJA, 2010).

Resultados mais modestos foram encontrados por Sheeja (2010) 
e Brindesi, Monopoli e Kapidakis (2013), quanto à consulta especificamente da biblioteca digital. Na pesquisa de Sheeja (2010) a frequência diária era de $17 \%$, enquanto para a maioria (28\%) a frequência era de duas a três vezes por semana.

Já os usuários investigados por Brindesi, Monopoli e Kapidakis (2013) não consultaram, especificamente, o sítio da biblioteca. Mas, indicaram gastar 5,42 horas por mês consultando outros sítios de interesse profissional.

Quanto ao objetivo de consulta da Biblioteca Eletrônica, 27,97\% apontaram a atualização do conhecimento e, em seguida, elaboração de pesquisas científicas $(24,92 \%)$, elaboração de relatórios, planos e programas $(16,72 \%)$, agronegócio $(11,90 \%)$, elaboração de cursos, palestras, dias de campo e outras atividades $(11,25 \%)$ e atendimento de consultas $(6,43 \%)$. Os outros motivos não foram significativos.

Já na pesquisa anterior, os resultados apontaram como objetivo principal elaboração de cursos, palestras e dias de campo, isto é, desenvolver suas atividades profissionais (SALVIATI; CASTRO, 2009).

No estudo de Sheeja (2010), a procura maior foi por questões de exame do ano anterior. Já no de Brindesi, Monopoli e Kapidakis (2013), a busca foi por bibliografia fornecida pelos professores e outras publicações. Ambos os trabalhos investigaram somente os estudantes de universidade, por isso a concentração das respostas voltadas às questões acadêmicas.

A maioria dos usuários, isto é, 228 (75,49\%) consultaram o sítio da Biblioteca Eletrônica à procura de mais de um assunto. $O$ número máximo de assuntos consultados por respondente foi de 6 (16 respondentes); o mínimo, 1 (74 respondentes); a média, 3,5; e o desviopadrão, 1,87. Analisando-se esse resultado, conclui-se que a maioria dos usuários $(75,49 \%)$ está explorando o conteúdo da biblioteca, pois não revela interesse por um assunto especifico. Em compensação, os demais $(24,50 \%)$, que consultaram apenas um assunto, indicam estar à procura de uma informação pontual. 
As consultas, no total de 876, foram agrupadas em 11 temas diferentes (Figura 4). Os temas mais relevantes foram: Produção vegetal (433); Recursos naturais e Meio ambiente (263); Produção animal (75); Economia agrícola (30); Desenvolvimento rural (19); Geografia e Geoprocessamento (7); Tecnologia alimentar (7); Engenharia rural e implementos (5); Biologia geral (4); Agroenergia (4); e Química (4).

Coincidentemente, Produção vegetal é o tema que possui maior número de publicações na Biblioteca Eletrônica (904), correspondendo a $49,37 \%$ do acervo total. Além disso, o tema Recursos naturais e Meio ambiente é o segundo em número de publicações da Biblioteca Eletrônica, 425 itens, correspondendo a $23,21 \%$ do acervo total.

Pequena porcentagem $(2,85 \%)$ dessas consultas foi classificada como inválida porque não indicaram um tema, mas reportaram-se a assuntos, tais como: pesquisas, teses, boletins, informações gerais, recomendações.

Comparando-se esses resultados com a pesquisa publicada em 2009, os três primeiros temas coincidem totalmente com os temas mais buscados naquela ocasião (SALVIATI; CASTRO, 2009). 
Figura 4 - Características dos Usuários: Temas pesquisados

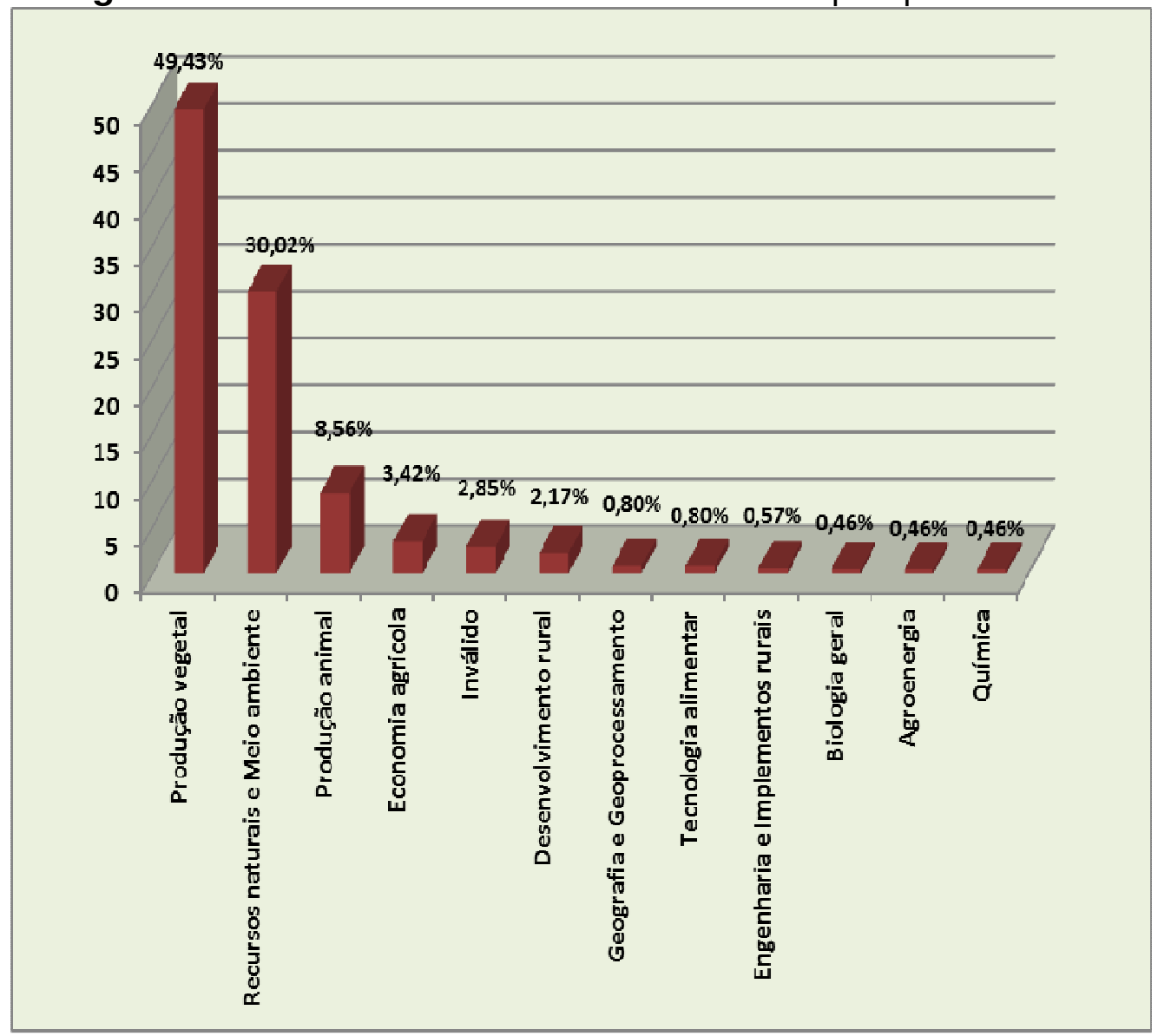

Fonte: Dados de pesquisa.

Examinando-se, particularmente, os subtemas de cada tema, obtiveram-se os seguintes resultados:

- $\quad$ Produção vegetal: foram encontrados 135 subtemas diferentes. Os mais frequentes foram: Pastagem (28); Agricultura em geral (20); Fitossanidade (17); Irrigação (17); Fruticultura nativa (16); Adubação (14); Fruticultura geral (14); Produção vegetal em geral (11); e Soja (10).

- Recursos naturais e Meio-ambiente: os usuários consultaram 69 subtemas diferentes com frequência variando de 1 a 36. Foi Cerrado (36) o mais frequente; seguido por Flora do Cerrado (34); Solos (32); Meio ambiente (15); Recuperação de áreas degradadas (14); e Recursos hídricos (11).

- Produção animal: 26 subtemas diferentes cuja frequencia variou de 1 a 16. Os mais frequentes foram: Bovinocultura geral (16); Bovinocultura de corte (7); Bovinocultura de leite (6); Nutrição animal (5); e Produção animal (5). 
- $\quad$ Economia agrícola: 15 subtemas, com frequência que variou de 1 a 7 . Foram os mais frequentes: Agronegócio (7); Custos de produção (5); Comercialização (4); e Administração rural (3).

- $\quad$ Desenvolvimento rural: teve apenas 7 assuntos diferentes e 19 consultas sobre o tema. $O$ assunto mais frequente foi Agricultura familiar (13). Os outros assuntos tiveram frequência muito baixa.

- $\quad$ Tecnologia alimentar: é um tema novo na Biblioteca Eletrônica. Ele surgiu em 2009 e arrola apenas 10 publicações. Surgiram 7 subtemas, todos com frequência 1.

- Biologia: surgiram apenas 4 consultas versando sobre Biologia molecular (2); Biologia geral (1); e Genoma (1).

- Geoprocessamento: surgiram 7 consultas sobre: Sensoriamento remoto (3); Agricultura de precisão (2); Geomorfologia (1); e Geoprocessamento em geral (1).

- $\quad$ Engenharia rural e Implementos: recebeu 5 consultas versando sobre: Construção rural (1); Estufas agrícolas (1); Implementos agrícolas (1); e Mecanização agrícola (2). É um tema com poucas publicações na Biblioteca Eletrônica.

Todas as consultas realizadas foram condizentes com o conteúdo da Biblioteca Eletrônica. Não houve assuntos fora das linhas de pesquisa da Embrapa Cerrados, como ocorreu na pesquisa publicada em 2009 (SALVIATI; CASTRO, 2009). Naquela pesquisa, 12,66\% dos assuntos não foram pertinentes, mostrando desconhecimento dos usuários de quais são as linhas de atuação da Embrapa Cerrados. Acredita-se que o fato de se ter escolhido os respondentes que já haviam consultado o sítio pelo menos duas outras vezes garantiu respostas mais fidedignas e mais úteis, principalmente no que concerne ao item seguinte que avalia os recursos do sítio.

\subsection{Opinião Acerca da Biblioteca Eletrônica da Embrapa Cerrados}

Nessa segunda parte da análise são apresentados e discutidos os resultados de avaliação do sítio propriamente dito. Reportam-se às respostas fornecidas por 303 usuários que preencheram ao questionário. 
Quanto à facilidade de consulta do sítio, quase metade (49,50\%) afirmou que ela é satisfatória; $33 \%$, fácil; e 12,43\%, muito fácil. Poucos indicaram haver dificuldade: 4,62\% apontaram como difícil e $0,33 \%$ como muito difícil. Especificamente, quanto à navegação no sítio, os usuários indicaram ser satisfatório (43,56\%), fácil $(40,26 \%)$ e muito fácil $(13,20 \%)$. Poucos indicaram ser difícil (2,64\%) e muito difícil (0,33\%).

$\mathrm{Na}$ pesquisa passada, os resultados foram similares, embora naquela ocasião investigou-se cada forma de consulta (autor, título, assunto e consulta avançada) separadamente (SALVIATI; CASTRO, 2009).

O trabalho de Brindesi, Monopoli e Kapidakis (2013) apontou que os usuários, apesar de se considerarem hábeis em recuperar informação, não gostam de recuperar informação em bases de dados. Eles preferem utilizar o Google e sítios da internet porque consideram ser mais fácil de recuperar informação. Além disso, foi constatado que eles não sabem utilizar os operadores booleanos, nem truncagem de termos e outros recursos avançados de busca.

Já no trabalho de Sheeja (2010), 94\% dos usuários afirmaram que a biblioteca digital é muito fácil de navegar e ressaltaram que as opções de busca e folheamento são muito úteis.

Os resultados antagônicos desses estudos mostram que, dependendo da biblioteca digital, pode haver divergência na avaliação de eficiência, facilidade e aceitação por parte dos usuários.

A opinião dos usuários sobre o tempo de resposta para carga das páginas e download de publicações foi satisfatória para $51,16 \%$ dos usuários; bom para 38,94\%; e ótimo para 7,92\%. Apenas 1,98\% consideraram péssimo. Esse tempo leva em conta outros fatores além da leveza do sítio e das publicações para download. Depende em grande grau da velocidade da rede utilizada pelo usuário e da capacidade de seu equipamento.

Apesar disso, o resultado foi muito bom e indica que os usuários não estão tendo dificuldade para usar o serviço. 
A questão a respeito do leiaute foi aberta. Nela, foi solicitado ao usuário escrever sua opinião. Obteve-se uma diversidade de respostas, que após a padronização, geraram 49 palavras-chave e ou frases diferentes que exprimiram a opinião deles sobre esse quesito. Apontaram como Bom, 129 usuários (43,14\%) e Muito bom 41 (13,71\%). Houve 7 usuários que deram resposta inválida e 5 usuários que não opinaram.

Não houve nenhuma avaliação negativa. Somente 4 usuários sugeriram modificação no leiaute.

Da mesma forma, a investigação da terminologia utilizada no sítio para busca por assunto foi realizada por questão aberta. $O$ procedimento foi o mesmo do utilizado para análise do leiaute. As respostas foram padronizadas e geraram 64 opiniões diferentes. A opinião de frequência maior é Boa, com $36,39 \%$ das respostas. Em seguida, Fácil com 8,50\%.

Grande parte das opiniões $(84,41 \%)$ foi positiva e não sugeriu qualquer melhoria. Porém, $14(5,78 \%)$ opiniões indicaram alguma dificuldade. Houve 10 respostas inválidas e 10 respostas sem avaliação.

Com relação à ajuda, grande parte dos usuários $(41,58 \%)$ não a consultou. Em compensação, 27,39\% a consideraram satisfatória; e $23,10 \%$, boa. O trabalho de Sheeja (2010) indicou quase o mesmo resultado: a maioria (53\%) não consultou a ajuda.

Para obtenção de sugestões dos usuários, foi elaborada uma questão aberta em que eles podiam opinar sobre melhoria do sítio. Grande parte dos usuários, isto é, 63,05\% não responderam; o restante $(36,95 \%)$ respondeu e contribuiu muito. As respostas obtidas foram reunidas por assunto, condensadas e geraram 54 opiniões diferentes. Para facilitar, essas opiniões foram agrupadas nos seguintes tópicos: desenvolvimento da coleção; divulgação; melhoria do sítio; e melhoria da estrutura de assunto.

As principais sugestões foram relativas ao desenvolvimento da coleção disponível: acrescentar mais publicações; incluir outros temas; 
incluir livros; disponibilizar fotos; disponibilizar vídeos; incluir mais animações; e hospedar publicações de outras instituições.

Sobre melhorar a divulgação do sítio, sugeriram: divulgar mais; destacar o sítio; e enviar email informando novas publicações incluídas.

A falta de promoção ou de marketing adequado para os produtos elaborados pelos serviços de informação é um problema persistente, constatado por outros estudos de usuários realizados há mais de 20 anos (FIGUEIREDO, 1994).

Quanto à melhoria do sítio, sugeriram: aumentar a velocidade; facilitar a navegação; melhorar a busca por autor; facilitar a busca em geral; criar histórico das buscas realizadas; destacar as notícias; incluir informações sobre os pesquisadores; integrar com outros Centros da Embrapa; manter link para sugestões, críticas e problemas; melhorar o leiaute e a interatividade; e realizar avaliações periódicas.

Quanto à melhoria da consulta de assuntos, sugeriram: apresentar a estrutura de assunto na primeira página; melhorar a estrutura de assunto; simplificar a terminologia; e utilizar assuntos normalizados.

As outras sugestões foram muito gerais e não contêm informação suficiente para qualquer iniciativa de melhoria.

\section{CONCLUSÕES}

Este trabalho contribuiu para maior conhecimento dos usuários da Biblioteca Eletrônica da Embrapa Cerrados. Constatou-se que o público principal é oriundo da região Centro-Oeste, especificamente do Distrito Federal. São estudantes e engenheiros-agrônomos, jovens de até 30 anos, que pertencem às universidades, escolas superiores e outras instituições de ensino, que estão em busca, principalmente, de atualizar o conhecimento.

Foram pouco significativas as consultas dos agronegócios, extensão rural, cooperativas e sindicatos rurais cujo objetivo era a solução de problemas e consultoria. Esse resultado mostra que 0 
serviço prestado pela Biblioteca Eletrônica atinge pouco uma fatia importante do agronegócio brasileiro - o público oriundo de sítios, fazendas e empresas agropecuárias, de empresas de extensão rural, cooperativas e sindicatos.

Para esse público, é necessário projetar serviços direcionados, contendo informações mais práticas, com terminologia menos técnica. $\mathrm{A}$ elaboração de um sítio específico da área de transferência poderia incluir os vídeos já disponíveis dos Dias de campo da TV, os programas de Prosa Rural, notícias, agenda de eventos e catálogo de publicações. Além disso, seria muito útil tornar disponíveis as perguntas $\mathrm{x}$ respostas já formuladas pelo Serviço de Atendimento ao Cidadão, para que o usuário pudesse recuperá-las por assunto. $O$ desenvolvimento de serviços desse tipo contribuiria muito para preencher a lacuna existente.

Os resultados de avaliação do sítio indicaram que os usuários estão satisfeitos com o serviço. A grande maioria considerou que o tempo de carga das páginas, a consulta, a navegação e a ajuda são satisfatórias. O leiaute e a terminologia empregada foram considerados bons.

Os resultados relativos à facilidade de consulta e de navegação coincidem com os apurados por Sheeja (2010). Embora ambas as bibliotecas digitais sejam diferentes em muitos aspectos, coincidentemente, incluem recursos de folheamento e busca. Os recursos de navegação por hipertexto em listas alfabéticas de autor, título, palavras-chaves e estruturas de assunto facilitam a busca de informação e podem ser decisivas para o sucesso da biblioteca digital.

A importância desses recursos é inferida pelos resultados de Brindesi, Monopoli e Kapidakis (2013) que mostraram que o usuário tem dificuldades para buscar informação por query. A estratégia de busca que ele elabora é muito rudimentar. Limita-se, muitas vezes, na expressão de apenas um termo.

No entanto, o uso de recursos apropriados é imprescindível para a obtenção de resultados satisfatórios. 
Para amenizar o desconhecimento dos mecanismos de busca pelos usuários, é necessário que a biblioteca digital disponibilize recursos mais fáceis, tais como, estruturas de assunto e listas alfabéticas que oferecem consultas por folheamento. É, também, muito útil projetar sistemas de busca com recursos inteligentes como aqueles proporcionados pelo Google, que evitam a memorização de operadores e sintaxe de busca.

Como recomendação final, sugere-se a realização de estudos complementares com o objetivo de explorar os padrões de uso da Biblioteca Eletrônica da Embrapa Cerrados por cada categoria de usuários: estudantes, pesquisadores, extensionistas, agricultores, profissionais de diversas áreas e leigos. E, mais além, avaliar a coleção de publicações quanto aos aspectos de utilidade, abrangência e qualidade.

\section{REFERÊNCIAS}

BAPTISTA, Sofia Galvão; CUNHA, Murilo Bastos da. Estudo de usuários: visão global dos métodos de coleta de dados. Perspectivas em Ciência da Informação, Belo Horizonte, v. 12, n. 2, p. 168-184, maio/ago. 2007.

BRASIL é o terceiro país em número de usuários ativos na internet. 2013. Disponível em <http://www.ibope.com.br/ptbr/noticias/paginas/brasil-e-o-terceiro-pais-em-numero-de-usuariosativos-na-internet.aspx>. Acesso em: 23 abr. 2014.

BRINDESI, Hara; MONOPOLI, Maria; KAPIDAKIS, Sarantos. Information seeking and searching habits of Greek physicists and astronomers: a case study of undergraduate students. In:

INTERNATIONAL CONFERENCE ON INTEGRATED INFORMATION (IC-ININFO 2012), 2., 2012, Budapest. Procedia: Social and Behavioral Sciences, Victoria, v. 73, p. 785-793, Feb. 2013.

DADOS, estatísticas e projeções sobre a Internet no Brasil. 2012. Disponível em: <http://tobeguarany.com/internet_no_brasil.php>. Acesso em: 23 abr. 2014. 
FIGUEIREDO, Nice Menezes de. Estudos de uso e usuários da informação. Brasília: IBICT, 1994.

HU, Chang-Ping; HU, Yuan; YAN, Wei-Wei. An empirical study of factors influencing user perception of university digital libraries in China. Library \& Information Service Research, Massachusetts, v. 36, n. 3-4, p. 225233, Apr. 2014.

LIEW, Chern Li. Digital library research 1997-2007: organizational and people issues. Journal of Documentation, London, v. 65, n. 2, p. 245266, 2009.

PERFIL da audiência por gênero. 2012. Disponível em: <http://www.cetic.br/usuarios/ibope/w-tab02-03.htm>. Acesso em: 23 abr. 2014.

ROZADOS, Helen Frota; PIFFER, Bárbara Pilatti. Pesquisa de Marketing e Estudos de Usuário: um paralelo entre os dois processos. Em Questão: Revista da Faculdade de Biblioteconomia e Comunicação da UFRGS, Porto Alegre, v. 15, n. 2, p. 169-182, jul./dez. 2009.

SALVIATI, Maria Elisabeth (Org.). Estrutura de assuntos. Planaltina: Embrapa Cerrados, 2012.

SALVIATI, Maria Elisabeth; CASTRO, Rosângela Lacerda de. Biblioteca eletrônica da Embrapa Cerrados: modelo conceitual, desenvolvimento, implantação e avaliação. Planaltina: Embrapa Cerrados, 2009. (Documentos, 245).

SARACEVIC, Tefko. Evaluation of digital libraries: an overview. In: DELOS WORKSHOP ON THE EVALUATION OF DIGITAL LIBRARIES, 2004, Padova. Proceedings... Padova: University of Padua, 2004.

SHEEJA, N. K. Undergraduate students' perceptions of digital library: a case study. The International Information and Library Review, London, v. 42, n. 3, p. 149-153, Sept. 2010.

VALLS, Valéria Martin; VERGUEIRO, Waldomiro de Castro Santos. A gestão da qualidade em serviços de informação no Brasil: uma nova revisão de literatura, de 1997 a 2006. Perspectivas em Ciência da Informação, Belo Horizonte, v. 11 n. 1, p. 118-137, jan./abr. 2006.

WHITMIRE, Ethelene. Disciplinary differences and undergraduates' information-seeking behavior. Journal of the American Society for Information Science and Technology, New York, v. 53, n. 8, p. 631638, 2002. 


\title{
Title
}

Electronic Library of Embrapa Cerrados: user study

\begin{abstract}
Introduction: This paper presents the results of research conducted with Electronic Library users - website, created in 2004 by Embrapa Cerrados, that organizes, stores, and provides full text of the technical scientific production published by the Institution.

Objective: To explore the user profile and to make an accurate assessment of the website. Methodology: Data collection of demographic aspects; habits; and search features: navigation, loading time of pages, help, layout and terminology by an online survey. Analysis by SPSS software - Statistical Package for the Social Sciences.

Results: The main users are students and agronomists, young people up to 30 years old, coming from the Federal District, belonging to universities and high schools wishing to update knowledge. After, appear the users of public agencies; private companies; Embrapa; agribusiness; federal government; schools; associations and non-governmental organizations; rural extension; cooperatives and syndicates. These users have no difficulties to use the service.

Conclusions: The service works well, but some suggestions are useful to improve it. In addition, little demand coming from farms, ranches, rural extension services, cooperatives and syndicates indicates the need to design new products and services oriented to such public.
\end{abstract}

Keywords: Electronic library. User survey. Information retrieval. Agricultural technology.

\section{Titulo}

Biblioteca Electrónica de Embrapa Cerrados: estudio de usuarios

\section{Resumen}

Introducción: Se presentan los resultados de la investigación realizada con los usuarios de la Biblioteca Electrónica de EMBRAPA Cerrados, creada en 2004, que organiza, almacena y pone a disposición, en texto completo, la producción técnico-científica de la institución.

Objetivo: Explorar el perfil del usuario y hacer una evaluación precisa del sitio.

Metodología: Recolección de datos demográficos; hábitos; y capacidades de consulta: navegación, tiempo de carga de páginas, ayuda, diseño y terminología por una encuesta en línea. Análisis de datos mediante el programa SPSS - Statistical Package for the Social Sciences.

Resultados: Los usuarios principales son estudiantes y agrónomos, de hasta 30 años, procedentes del Distrito Federal, pertenecientes a universidades y escuelas superiores, que buscan actualizar conocimientos. A continuación, aparecen los usuarios de organismos públicos; empresas privadas; Embrapa; agroindustria; gobierno federal; colegios y escuelas; asociaciones y 
organizaciones no gubernamentales; extensión agraria; cooperativas y sindicatos. Estos usuarios no tienen dificultades para utilizar el servicio.

Conclusiones: El servicio atiende bien, pero, algunas propuestas son útiles para mejorar lo. Por otra parte, el hallazgo de poca demanda proveniente de los ranchos, haciendas, empresas de extensión agraria, cooperativas y sindicatos indica la necesidad de diseñar nuevos productos y servicios dirigidos a ese otro público.

Palabras clave: Biblioteca digital. Estudio de usuario. Recuperación de la información. Tecnología agrícola.

Recebido em: 11/07/2014

Aceito em: 26/05/2015 